\title{
Exploring factors affecting anther culture in rice (Oryza sativa L.)
}

\author{
Swapan Kumar Tripathy*, D. Swain, P. M. Mohapatra, Arjun M. Prusti, Bandita Sahoo, Sucharita Panda, \\ Monalisha Dash, Bhaskar Chakma, Suraj K. Behera \\ Department of Agricultural Biotechnology, College of Agriculture, Orissa University of Agriculture and Technology, Bhubaneswar, Odisha, India
}

\begin{tabular}{|c|c|}
\hline $\begin{array}{l}\text { Article history: } \\
\text { Received on: March 13, } 2018 \\
\text { Accepted on: August 19, } 2018 \\
\text { Available online: January } 24,2019\end{array}$ & $\begin{array}{l}\text { Anther culture is an important in vitro culture technique for the production of double haploids. It is largely species } \\
\text { and genotype specific. Asian-cultivated rice (Oryza sativa, ssp. indica) is recalcitrant to anther culture which limits its } \\
\text { practical application in rice breeding. Several researchers tried to optimize the medium recipes and culture techniques } \\
\text { for callus induction and plantlet regeneration. Negligible response to callus induction and recovery of a higher }\end{array}$ \\
\hline $\begin{array}{l}\text { Key words: } \\
\text { Anther culture, } \\
\text { Double haploids, } \\
\text { Factors for anther culture, } \\
\text { Genetic improvement, } \\
\text { Rice }\end{array}$ & $\begin{array}{l}\text { frequency of albino plants are the major hindrance for the use of the technique in crop improvement. Shortening the } \\
\text { culture period and sexual hybridization of rice subgroups (japonica/indica) may be adopted to improve green plant } \\
\text { regeneration from anther-derived callus in indica rice. However, genetic transformation technology using individual } \\
\text { genes related to different aspects of anther culture could be a more direct approach. Besides, the role of genotypes, } \\
\text { physiological status of donor plant, developmental stage of pollen, pre-treatment, culture media, phytohormones, and } \\
\text { culture conditions for successful anther culture have been discussed. }\end{array}$ \\
\hline
\end{tabular}

\section{INTRODUCTION}

Rice (Oryza sativa L., $2 n=24$, Family Poaceae) provides food to over half of the global population [1]. Rice is being highly selfpollinated; development and selection of pure breeding lines with manifested superior phenotype are the ultimate objective for desired genetic improvement. In this context, anthers of $F_{1}$ hybrids can serve as excellent breeding material for raising pollen-derived homozygous plants (double haploids [DHs]). Such DH plants are individually genetically unique due to gene shuffling (during micro-gametogenesis) which paves the way for the selection of desirable plants with high yield potential and biotic/abiotic stress tolerance. Besides, anther culture offers a greater chance of recovery of desirable recessive genes compared to conventional breeding. Asian cultivated rice (O. sativa ssp. indica) is recalcitrant to anther culture which limits its practical application in rice breeding. However, the benefit of this technique can be successfully harnessed if a reproducible protocol for anther culture is available. Several researchers tried to optimize the media recipes and culture techniques for callus induction and plantlet regeneration. Negligible response to callus induction and recovery of a higher frequency of albino plants are the major hindrance for the use of the technique in crop improvement. In this pursuit, we present the finding of our extensive reviews on factors determining successful anther culture response in rice.

*Corresponding Author:

Swapan Kumar Tripathy,

Department of Agricultural Biotechnology, College of Agriculture, Orissa

University of Agriculture and Technology, Bhubaneswar, Odisha, India.

Email: swapankumartripathy@gmail.com

\section{ANTHER CULTURE IN RICE}

Anthers, in general, are very sensitive to in vitro culture. The accidental discovery of androgenic haploidy in Datura by Guha and Maheswari [2] led several researchers to attempt such novel technique in a wide range of crop plants. Haploid plant production was first reported in rice through anther culture by Niizeki and Oono [3]. Anther culture is a two-step process [Figure 1]. First step is the initial development of callus that leads to the second step, i.e., regeneration of green plants from callus. Limited morphogenetic potential of antherderived calli and a higher percentage of regenerated albino plants [4] seem to be major constraints for DH breeding. Gueye and Ndir [5] reported the recovery of a total of 93 regenerants, of which 79 were albinos. Therefore, optimization of culture variables is often required for the successful use of anther culture.

\section{FACTORS AFFECTING ANTHER CULTURE}

The success of anther culture depends on exogenous and endogenous factors such as maturity of the donor plant, genotype, microspore developmental stages, panicle pretreatment, temperature and duration of pretreatment, culture media, and growth conditions.

\subsection{Genotype}

Response to anther culture varies differently within species, subspecies, or varieties. Oryza glaberrima is more potent for callusing and regeneration than $O$. sativa [5]. Japonica types are in vogue more responsive to microspore embryogenesis than indica types in rice. Many researchers have reported genotypic specificity within indica subspecies using improved media [4]. Indica cultivars show poor 


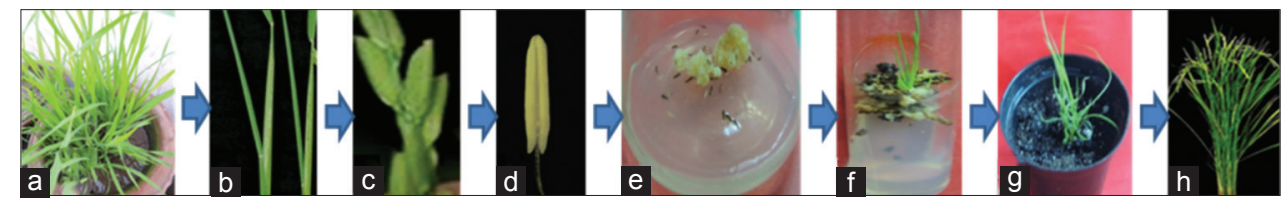

Figure 1: Anther culture-derived plantlet production in rice. (a) Rice plant as source of explants, (b) boots, (c) spikelets, (d) anther, (e) callus induction from anthers, (f) regeneration of plantlet, (g) plant establishment in pot mixture, and (h) field grown plants at panicle stage

callus growth, poor regeneration ability, and low percentage of albino plants [6]. Only 5 of 18 indica cultivars showed pollen callusing and 4 calli differentiate into plants [7], whereas only 1 of 35 indica cultivars exhibited pollen callusing [8]. Tran and Vuong [9] also recorded low response for callus induction $(3.53 \%)$ and plantlet regeneration $(1.12 \%)$ frequency in indica rice. However, combining high yielding indica rice with high anther culture responding japonica genotype may improve anther culture response [10]. Thuan et al. [11] reported high callus induction frequency from anthers of $F_{1}$ plants derived from four crosses of aromatic and improved rice cultivars. Calli from a $\mathrm{F}_{1}$ hybrid (Bg 90-2: Indica rice/Hu Lo Tao: Japonica rice) showed a higher frequency of green plantlet regeneration than their parents. High callus induction frequencies (30-34\%) and low regeneration response in $\mathrm{F}_{1} \mathrm{~s}$ were obtained by Mishra et al. [12], while positive relationship for both was noticed by Javed et al. [13] and Shahnewaz et al. [14]. Dash et al. [15] reported a callus induction frequency of as high as $37.83 \%$ from anther culture of a cross CRMS31B/CRMS24B. However, genetic transformation technology using individual genes related to different aspects of anther culture could be a more direct approach to improve green plant regeneration.

\subsection{Physiological Status of Donor Plant}

Anthers collected at the beginning of the flowering period respond better, and it declines with the age of plants [16]. Field-grown plants show superiority over to those grown in the glasshouse or pots [17]. Plants with excessive vegetative growth are not desirable, and therefore, second application and/or foliar spray of nitrogen is avoided. Besides, a favorable day $\left(34^{\circ} \mathrm{C}\right)$ and night $\left(25^{\circ} \mathrm{C}\right)$ temperatures at booting stage seem to be a determining factor for androgenic embryogenesis [18]. Anthers from the primary tillers are in vogue more responsive than secondary tillers [19]. Besides, physiological status of anthers from the middle portion of the panicles in boot stage seems to be favorable for callusing and regeneration [20].

\subsection{Developmental Stage of Pollen}

The developmental stage of pollen can enhance anther culture efficiency. In rice, the most suitable stage is the early to mid-uninucleate pollen stage [21], while the older pollens at tetrad stage and after the first pollen mitosis do not respond to culture due to starch deposition leading to differentiation into male gametophyte [22]. Such above appropriate condition corresponds to the 3-4 cm distance between the collar of the flag leaf and ligule of the penultimate leaf [23]. Therefore, it is important to optimize the anther culture response in rice by assessing the optimum developmental stage of pollen grain in the anther by acetocarmine staining.

\subsection{Pre-treatment}

Anthers exposed to various kinds of stresses (cold, heat, osmotic stress, sugar starvation, gamma irradiation, and chemical treatment) before in vitro culture are reported to induce androgenesis [24] and inhibit callus induction from somatic origin (anther wall and tapetum).
However, the type and duration of pre-treatments vary with the species and variety of rice [25].

\subsubsection{Cold pre-treatment}

A low-temperature stress has been reported to induce and ensure continuance of sporophytic mode of the development of microspores [26] instead of follow-up gamete formation. It triggers embryogenesis from microspores [27] and increases the frequency of spontaneous development of DH plants [28]. Green plant regeneration is reported to be enhanced by 6 days of cold pretreatment to the panicles [29]. Pre-treatment of anthers at $10^{\circ} \mathrm{C}$ for $11-12$ days [30] results in better callusing response but led to albino plantlet regeneration, while pretreatment at $12^{\circ} \mathrm{C}$ for 5 days gives best regeneration response [31]. Besides, cold pre-treatment eliminates weak or non-viable microspores in culture [32], delays anther wall senescence, and increases the symmetric division of pollen grains and release of necessary substances (cold shock proteins and amino acids) for androgenesis [33].

\subsubsection{Heat shock treatment}

Heat temperature pre-treatment synchronizes physiological states of microspores and stimulates embryoid formation by disrupting the cytoskeleton at the initial stage of microspore development [34].

\subsubsection{Osmotic stress}

Osmotic stress, for example, mannitol can offer as a substitute or replace the pre-cold treatment as it enables physiological isolation microspores [35] leading to embryoid formation. It improves the sugar uptake causing increased glucose level in the anther tissue. Treatment of anthers in $0.4 \mathrm{M}$ mannitol was useful to enhance androgenesis in anther culture of indica cultivar IR 43 from 3\% to 33\%. However, cold treatment combined with mannitol-induced osmotic stress had no added advantage [36] or even detrimental.

\subsubsection{Sugar starvation}

Sugar starvation contributes to the promotion of high-frequency embryogenesis and plantlet regeneration from microspores isolated from anthers of indica and japonica rice and also in isolated microspores [37]. Sugar starvation of anthers of indica rice variety IR 43 for 2 days at the beginning of culture caused a 12 -fold increase in the androgenic response in this variety [38]. However, cold treatment was superior to sugar starvation. Touraev et al. [39] reported better anther culture response by starvation of anthers in sugar-free medium in wheat.

\subsubsection{Gamma radiation}

Low irradiation pre-treatment is known to promote embryogenesis in anther culture. Chen et al. [40] reported significant stimulatory effect of $20 \mathrm{kR}$ gamma ray treatment on the regeneration of green plantlets. Similarly, Mkuya et al. [41] observed prolific DH production and green plant regeneration following gamma-irradiation of indica rice line TM7-5.

\subsubsection{Chemical treatment}

Ethrel and ethephon (ethylene releasers) have pronounced effect in haploid production in various plant species. Plants are sprayed 
with $4000 \mathrm{ppm}$ ethrel just before meiosis in pollen mother cells which result in multinucleated (4-6) pollen with fewer starch grains. Parthenogenetic embryoids may be induced due to additional mitosis from such pollen grains in culture [42]. Wang et al. [43] reported enhancement in anther culture response with $4000 \mathrm{ppm}$ ethrel (2-chloroethyl phosphonic acid) treatment for $48 \mathrm{~h}$ at $10^{\circ} \mathrm{C}$. Besides, androgenic response of rice anthers was enhanced if the inflorescences were pre-treated with ethrel. Similarly, Wang et al. [44] reported a positive effect of ethephon on mitotic activity of microspores.

\subsection{Culture Media}

Haploid plants can be produced either through embryo formation [45] or callusing [3] by varying medium composition. N6 [46], MS [47], and $\mathrm{SK}_{1}$ [48] solid media are in vogue used for anther culture and the former is being more potent than two later media [49] and even compared to MO19 [50], Blayde's [51], MSN1, SK8, and R2 (modification of MS medium) for callus induction [50] and green plant regeneration [12]. Frequency of callus formation was better in N6 medium as compared to MS medium (11.9\% and 7.95\%, respectively) [11]. Lentini et al. [8] favored liquid media for callus induction as it provides greater access to nutrients and hormones, and there are chances of more rapid dispersion of toxic substances [6]. Choice of media proves to be genotype specific [4]. Khanna and Raina [52] indicated significant genotype $\mathrm{x}$ culture media interaction for regeneration response in three indica rice cultivars. N6 media respond better to anther culture in japonica than indica [8]. Kaushal et al. [53] reported the highest callus induction, green plant regeneration, and least albino plant development of $40.64 \%, 40.93 \%$, and $3.72 \%$, respectively, in He-2 medium [54].

Higher doses of nitrogen, phosphorus, and potassium in the media led to better anther culture response in indica rice [22]. In general, ammonium nitrogen $\left(\mathrm{NH}_{4}^{+}\right)$is required in low amount for anther culture in cereal. N6 medium being high in $\mathrm{NO}_{3}{ }^{-}$and low in $\left(\mathrm{NH}_{4}^{+}\right)$ has proved to be very efficient for japonica rice anther culture [55]. Sucrose and iron are crucial for pollen embryo development [56] and chelated form of iron (Fe-EDTA: Iron-Ethylenediamine tetraacetic acid) is more effective than ferric citrates [57]. Maltose showed better callusing and regeneration response than sucrose. Besides, a higher ratio of green plantlets to albinos in both japonica and indica types was realized due to mannitol as carbon source [13]. Alternatively, ficoll-a synthetic polymer of sucrose could be used to increase the surface density and improve the ratio of green to albino plantlets [58] and to maintain optimum osmotic pressure. Gel rite is another gelling agent found to be the most effective one [59]. Addition of organic additives (yeast extracts at $100 \mathrm{mg} / 1$, casein hydrolysate at $500 \mathrm{mg} / 1$, and coconut water 5-10\%) to N6 further enhanced androgenic callus induction in indica rice varieties [60]. Besides, the requirement of amino acids, for example, glutamine and alanine is realized in indica rice for callus formation and green plant regeneration [38]. $\mathrm{AgNO}_{3}$ supplementation can induce a callusing response and promote the regeneration of green plants [61].

\subsection{Hormonal Requirement}

2,4-dichloro-phenoxyacetic acid (2,4-D) and naphthalene acetic acid (NAA) alone or with kinetin in the culture medium seem to be the major determinants for embryogenic callusing from rice anthers [62]. Neither 2,4-D nor NAA alone in the media can support regeneration, but the use of cytokinins such as kinetin $(\mathrm{Kn})$ and 6 benzyl aminopurine (BAP) with NAA is required for regeneration. A combination of $0.5 \mathrm{ppm}$ indole acetic acid (IAA) and $2.0 \mathrm{ppm}$ facilitates the germination of androgenic embryos. IAA and NAA may induce direct androgenesis, while 24 -D promotes callus induction and rapid cell proliferation [63]. A lower concentration of BAP enhances microtillering from androgenic plantlets [64], and NAA promotes the formation of roots. Thuan et al. [11] reported better callus induction from anthers of $F_{1}$ plants derived from four crosses of aromatic and improved rice cultivars cultured in N6 and MS media supplemented with 2,4-D $(0.5 \mathrm{mg} / \mathrm{L})+\mathrm{NAA}(1.0 \mathrm{mg} / \mathrm{L})+$ BAP $(0.5 \mathrm{mg} / \mathrm{L})$. Niroula and Bimb [65] reported higher callus induction frequency in N6 medium with $2,4-\mathrm{D}(2.5 \mathrm{mg} / \mathrm{l})+0.5 \mathrm{mg} / \mathrm{l} \mathrm{Kn}$ than N6 + NAA $(4 \mathrm{mg} / \mathrm{l})+\mathrm{Kn}(0.5 \mathrm{mg} / \mathrm{l})$; however, reverse was the case for green plant regeneration. Xa and Lang [66] reported 5.13-9.27\% callus induction and $6.17-14 \%$ regeneration from four crosses in MS medium with combination $1 \mathrm{mg} / \mathrm{L} \mathrm{BA}+2 \mathrm{mg} / \mathrm{L} \mathrm{Kn}+3 \%$ sucrose. Besides, MS medium with $10 \%$ coconut milk and addition of $\mathrm{Kn}(0.5 \mathrm{mg} / 1)$, BAP $(2 \mathrm{mg} / 1$, ) and NAA (1 mg/1) at ratio of 1:4:2 gave consistently high frequency of plantlet regeneration from anther derived calli of a wide range of genotypes [67].

Embryo formation (10.8\%) was reported to be markedly increased by abscisic acid in the callus induction media or its treatment during the cold pre-treatment period [68]. Ethylene is also produced in plant cell due to the presence of auxin [69], sucrose [70], or calcium [71] in the callus induction medium. Profused callusing may be due to the inhibitory effect of endogenously produced ethylene from excised anthers [72]. Polyamines [73] and $\mathrm{AgNO}_{3}$ [8] also affect anther culture response in rice through inhibition of ethylene synthesis. Putrescine application to the callus medium also increases the frequency of green/ albino regeneration frequency both in japonica and indica variety.

\subsection{Culture Condition}

Anther derived callus was observed in Azucena rice variety (6.66\%) while no callusing was found in Budda variety when the cultures were exposed to dark at $23 \pm 2{ }^{\circ} \mathrm{C}$ [74]. Highest callus induction was observed from the anther culture of rice variety Rajalaxmi and Ajay by keeping the culture at $25 \pm 1{ }^{\circ} \mathrm{C}$ for 3-4 weeks [12] and from anthers of six $\mathrm{F}_{1}$ hybrids within 60 days, and highest regeneration frequency was obtained by keeping at $18 \mathrm{~h}$ photoperiod with a light intensity of $27 \mu \mathrm{mol} \mathrm{m} \mathrm{m}^{-2} \mathrm{~s}^{-1}$ at $25 \pm 1^{\circ} \mathrm{C}$ [75] which was also observed in japonica variety (Mankeumbyeo, recurrent parent) and a recalcitrant indica variety (Ranta Emas, donor parent) at the same culture condition [76].

Culturing of anthers of PT-1, KDML-105, and HJ rice variety at $25 \pm 2{ }^{\circ} \mathrm{C}$ in darkness for 6 weeks successfully induced embryogenic calli [77]. Highest callus induction frequency was obtained in anther culture of japonica/indica and indica/japonica hybrids [78] at $25 \pm$ $2^{\circ} \mathrm{C}$ for 8 weeks. Androgenic callus induction as well as green plantlet regeneration was observed by keeping anther culture of five indica rice genotypes (IR 72, Mansarovar, Taraori Basmati, Pusa Basmati, and Karnal local 95) [61] and indica rice genotypes (GR 11 and Gurjari) in the dark at $25 \pm 2{ }^{\circ} \mathrm{C}$ [79]. Callus induction frequency and regeneration efficiency at $30^{\circ} \mathrm{C} / 20^{\circ} \mathrm{C}$ day/night temperature in the dark for 4 weeks were increased 1.4 times and more than double, respectively, than when kept at $25^{\circ} \mathrm{C}$ [80]. Initial incubation in the dark at $26 \pm 2{ }^{\circ} \mathrm{C}$ for 6 weeks followed by $12 \mathrm{~h}$ photoperiod for another 2 weeks resulted highest callus induction and plant regeneration response in six indica (HKR120, HKR 86-3, HKR86-217, PR106, Gobind, and CH 2 double dwarf) and two basmati rice (Basmati 370 and Taraori Basmati) varieties and 14 heterotic indica Basmati $F_{1}$ hybrids [23]. Callus induction was also observed by incubating at $27^{\circ} \mathrm{C}$, but regeneration ability was lost after 11 days [40]. In contrast, incubation at the above temperature was satisfactory in an interspecific hybrid (O. sativa L./Oryza rufipogon) for callus induction in the dark and for plantlet regeneration in $16 \mathrm{~h}$ photoperiod 
(2000 lux) [81]. However, callus induction frequency $(0.75-5.15 \%)$ was found from anthers of two indica elite lines (MRP5401 and BR29) and one japonica variety (Taipei 309) with exposure in white light for $16 \mathrm{~h}$ at $28 \pm 20^{\circ} \mathrm{C}$ until shoots development in about 3-6 weeks [82].

Recovery of a higher frequency of albino plants [4] in regeneration media is a serious problem, and it may be primarily due to breakage of DNA in plastids and nuclei [83]. The frequency of albinism among regenerated plants is controlled by quantitative trait loci on chromosome 9 and 10 [84]. Albinism is reported to be reduced by shortening of culture period [85]. Therefore, fresh calli (3-4 mm diameter) induced in primary culture may be preferred for transfer to regeneration media without allowing subculturing for callus proliferation.

\section{CONCLUSION}

In rice, several breeding methods are now available to broaden genetic variation and recovery of desirable gene combinations. Each anther of a intervarietal/interspecific hybrid carries thousands of pollen grains with different genotypes, and these can be induced to form stable DH plantlets within short time. Several factors, for example, genotype, physiological status of source plant, pollen stage, media recipes, including hormonal supplementation, pre-treatment of anthers, and culture conditions determine the success of anther culture. A highly reproducible anther culture technique with optimized culture variables can accelerate the breeding process for the isolation of plant types with high yield, disease resistance, and improved quality traits. Besides, the technique once optimized; it can be used to detect and fix (by colchicine) desirable recessive traits induced through mutation or spontaneous gametoclonal variation.

\section{ACKNOWLEDGMENTS}

We sincerely acknowledge and thank all researchers for their valuable contributions included in this pursuit.

\section{REFERENCES}

1. Sasaki T. The maped base sequence of the rice genome. Nature 2005;436:793-800.

2. Guha S, Maheswari SC. In vitro production of embryos from anthers of Datura. Nature 1964;204:497.

3. Niizeki $\mathrm{H}$ and Oono K. Induction of haploid rice plant from anther culture. Proc Jap Acad. 1968; 44:554-7.

4. Talebi R, Rahemi MR, Arefi H, Nourozi M, Bagheri N. In vitro plant regeneration through anther culture of some Iranian local rice (Oryza sativa L.) cultivars. Pak J Biological Sci 2007;10:2056-60.

5. Gueye T, Ndir KN. In vitro production of double haploid plants from two rice species (Oryza sativa L. and Oryza glaberrima Steudt.) for the rapid development of new breeding material. Sci Res Essays 2010;5:709-13.

6. Raina SK. Doubled haploid breeding in cereals. Plant Breed Rev 1997;15:141-86.

7. Guha-Mukherjee S. Genotypic differences in the in vitro formation of embryoids from rice pollen. J Exp Bot 1973;24:139-44.

8. Lentini Z, Reyes P, Martinez CP, Roca WM. Androgenesis in highly recalcitrant rice genotypes with maltose and silver nitrate. Plant Sci 1995;110:127-38.

9. Tran DG, Vuong DT. Effect of different media and genotypes on anther culture efficiency of $F_{1}$ plants derived from crosses between IR64 and new plant type rice cultivars. Omonrice 2002;10:107-9.

10. Herath HM, Bandara DC. Anther culture performance in selected high yielding Indica (of Sri Lanka) and japonica rice varieties and their inter sub-specific hybrids. J Nat Sci Found 2011;39:149-54.
11. Thuan OT, Tuan VD, Ba Bong B. Study on anther culture of $F_{1}$ plants from crosses between aromatic and improved rice cultivars. Omonrice 2001;9:41-5.

12. Mishra R, Rao RN, Rao GJ. Anther culture response of indica rice hybrids. Oryza 2011;48:375-7.

13. Javed MA, Ishi T, Kamijima O, Misoo S. The role of alternating culture temperatures and maltose in enhancing anther culture efficiency of salt tolerant indica rice (Oryza sativa L.) cultivars, Pokkali and Nona Bokra. Plant Biotechnol 2007;24:283-7.

14. Shahnewaz S, Bari MA, Siddique NA, Rahman MH. Effects of genotype on induction of callus and plant regeneration potential in vitro anther culture of rice (Oryza sativa L.). Pak J Biol Sci 2004; 7:235-7.

15. Dash AK, Rao JG, Rao RN. Effect of genotype on anther culture response in indica rice hybrids of maintainer lines. Oryza 2014; 51:165-7.

16. Szarejko I. Anther culture for double haploid production in barley (Hordeum valgare L.). In: Maluszynski M, Kasha K, Forster BP, Szarejko I, editors. Double Haploid Production in Crop Plants: A Manual. Dorsrecht, Netherlands: Kluwer; 2003. p. 35-42.

17. Veeraraghavan R. A Study on the Comparison of Anther Culture Response in Different Varieties of rice, Oryza sativa L. Subspecies Indica. University of Colombo. Colombo, Sri Lanka; 2007.

18. Prem D, Gupta K, Agnihotri A. Doubled haploids: A powerful biotechnological tool for genetic enhancement in oilseed Brassicas. In: Srivastava PS, Narula A, Srivastava S, editors. Plant Biotechnology and Molecular Markers. New Delhi, India: Anamaya Publishers; 2004. p. 18-30.

19. Asif M. History, production methods and types of haploids. In: Asif M, editor. Progress and Opportunities of Double Haploid Production. Canada: University of Alberta; 2013. p. 11.

20. Jacquard C, Asakaviciute R, Hamalian AM, Sangwan RS, Devaux P, Clement C. Barley anther culture: Effects of annual cycle and spike position on microspore embryogenesis and albinism. Plant Cell Rep 2006;25:375-81.

21. Datta SK, Wenzel G. Single microspore derived embryogenesis and plant formation in barley (Hordeum vulgare). Arch Zeucht 1998;18:125-31.

22. Silva TD. Indica rice anther culture: Can the impasse be surpassed? Plant Cell Tiss Organ Cult 2010;100:11-111.

23. Bishnoi U, Jain RK, Rohilla JS, Chowdhury VK, Gupta KR, Chowdhury JB. Anther culture of recalcitrant indica $\mathrm{x}$ basmati rice hybrids. Euphytica 2000;114:93-101.

24. Shariatpanahi ME, Bal U, Heberle-Bors E, Touraev A. Stresses applied for the re-programming of plant microspores towards in vitro embryogenesis. Physiol Plant 2006;127:519-34.

25. Datta SK. Androgenesis in cereals. In: Bhojwani SS, Soh WY, editors. Current Trends in Embryology of Angiosperms. Dordrecht: Kluwer Academic Publishers; 2001. p. 471-88.

26. Matsushima T, Kikuchi S, Takaiwa F, Oono K. Regeneration of plants by pollen culture in rice (Oryza sativa L.). Plant Tissue Cult Lett 1988;5:78-81.

27. Chen CC, Tsay HS, Huang CR. Factors affecting androgenesis in rice (Oryza sativa L.). In: Bajaj YP, editor. Rice Biotechnology in Agriculture and Forestry. Berlin; Springer Verlag; 1991. p. 193-211.

28. Amssa M, De Buyser J, Henry Y. Origin of diploid plants obtained by in vitro culture of anthers of young wheat (Triticum aestivum L.). Nat Acad Sci 1980;290:1095-7.

29. Sen C, Singh RP, Singh MK, Singh HB. Effect of cold pretreatment on anther culture of boro rice hybrids. Int J Plant Rep Biol 2011;3:69-73.

30. Gupta HS, Borthakur DN. Improved rate of callus induction from rice anther culture following microscopic staging of microspores in iron alum-haemotoxylin. Theor Appl Genet 1987;74:95-9.

31. Kaushal L, Sharma R, Balachandran SM, Ulaganathan K, Shenoy V. 
Effect of cold pretreatment on improving anther culture response of rice (Oryza sativa L.). J Exp Biol and Agric Sci 2014a;2:234-42.

32. Lenka N, Reddy GM. Role of media and plant growth regulators in callusing and plant regeneration from anthers of indica rice. Proc Indian Nat Sci Acad 1994;60:87-92.

33. Kiviharju E, Pehu E. The effect cold and heat pretreatments on anther culture response of Avena sativa and A. sterilis. Plant Cell Tiss Organ Cult 1998;54:97-104.

34. Ferrie AM, Keller WA. Development of Methodology and Applications of Doubled Haploids in Brassica rapa. In: Proceedings of the $9^{\text {th }}$ International Rapeseed Congress. Cambridge, UK; 1995. p. 807-9.

35. Wetherell DF. Enhanced adventitive embryogenesis resulting from plasmolysis of cultured wild carrot cells. Plant Cell Tiss Organ Cult 1984;3:221-7.

36. Pande H. Androgenesis in Other Cultures of an Indica Cultivar of Oryza sativa L. Ph.D. Thesis, University of Delhi; 1997. p. 56.

37. Raina SK, Ifran ST. High-frequency embryogenesis and plantlet regeneration from isolated microspores of indica rice. Plant Cell Rep 1998;17:957-62.

38. Ogawa T, Fukuwa H, Ohkawa Y. Plant regeneration through direct culture of isolated pollen grains in rice. Breed Sci 1995;45:301-7.

39. Touraev A, Indriato A, Wratschko I, Vicente O, Heberle-Bors E. Efficient microspore embryogenesis in wheat (Triticum aestivum L.) induced by starvation at high temperature. Sex Plant Reprod 1996;9:209-15.

40. Chen QF, Wang CL, Lu YM, Shen M, Afza R, Duren MV, et al. Anther culture in connection with induced mutations for rice improvement. Euphytica 2001;120:401-8.

41. Mkuya MS, Si HM, Liu WZ, Sun ZX. Effect of 137Cs gamma rays to panicles on rice anther culture. Rice Sci 2005;12:299-302.

42. Chawla HS. In vitro production of haploids. In: Introduction to Plant Biotechnology. $3^{\text {rd }}$ ed. New Delhi: Oxford And IBH Pub. Co. Pvt. Ltd.; 2010. p. 95.

43. Wang RF, Zuo QZ, Zheng SW, Tiang WZ. Induction of plantlets from isolated pollen culture in rice (Oryza sativa L.). Acta Genet Sin 1979;6:7.

44. Wang CC, Sun CS, Chu CC. On the conditions for the induction of rice pollen plantlets and certain factors affecting the frequency of induction. Acta Bot Sinica 1974;16:43-53.

45. Guha S, Lyer RD, Gupta N, Swaminathan MS. Totipotency of gametic cells and production of haploids in rice. Curr Sci 1970;39:174-6.

46. Chu CC, Wang CC, Sun CS, Hsu C, Yin KC, Bi CV. Establishment of an efficient medium for anther culture of rice through comparative experiments on the nitrogen source. Sci Sin 1975;18:659-68.

47. Murashige T, Skoog F. A revised medium for rapid growth and bioassay with tobacco tissue culture. Physiol Plant 1962;15:473-97.

48. Raina SK. Tissue culture in rice improvement: Status and potential. Adv Aron 1989;42:339-98.

49. Siddique R. Impact of different media and genotypes in improving anther culture response in rice (Oryza sativa) in Bangladesh. Eur Sci J 2015;11:164-9.

50. Raina SK, Zapata FJ. Enhanced anther culture efficiency of indica rice (Oryza sativa L.) through modification of the culture media. Plant Breed 1997;116:305-15.

51. Blaydes OF. Interaction of kinetin and various inhibitors in the growth of soybean tissue. Physiol Plant 1966;19:748-53.

52. Khanna HK, Raina SK. Genotype $x$ culture media interaction effects on regeneration response of three indica rice cultivars. Plant Cell Tissue Organ Cult 1998;52:145-53.

53. Kaushal L, Balachandran SM, Ulaganathan K, Shenoy V. Effect of culture media on improving anther culture response of rice (Oryza sativa L.). Int J Agric Innov Res 2014b;3:218-24.

54. Huang HG, Ling HS, Tseng PL, Shien YL, Shi P. Studies on Medium
Component in Anther Culture of Rice (O. sativa L.) sp. Hsien by Mathematical Methods. Proceedings Symposium: Plant Tissue Culture. Peking: Science Press; 1978. p. 244-6.

55. Grimes HD, Hodges TK. The inorganic NO3: NH4 ratio influences plant regeneration and auxin sensitivity in primary callus derived from immature embryos of indica rice (Oryza sativa L.). J Plant Physiol 1990;136:362-7.

56. Nitsch JP. Haploid plants from pollen. ZPflanzenzuchtg 1972;67:3-18.

57. Rashid A, Street HE. The development of haploid embryos from anther cultures of Atropa belladonna L. Planta 1973;113:263-70.

58. Lashermes P. Improved anther culture method for obtaining direct regeneration in wheat (Triticum aestivum L.). J Genet Breed 1992;46:99-102.

59. Lee JH, Lee SY. Effect of gelling agents and growth regulators on rice anther culture. Kor J Plant Tiss Cult 1995;22:35-9.

60. Roy B, Mandal AB. Anther culture response in indica rice and variations in major agronomic characters among androclones of a scented cultivar, Karna local. Afr J Biotechnol 2005;4:235-40.

61. Sah BP. Response of genotypes to culture media for callus induction and regeneration of plants from rice anthers. Sci World 2008;6:37-43.

62. Mukherjee A, Islam MR, Nasiruddin KM, Banerjee P. Study on callus initiation and plantlet regeneration ability of some rice genotypes. Int J Sci Tech Res 2015;4:354-61.

63. Ball ST, Zhou HP, Konzak CF. Influence of 2, 4-D, IAA, and duration of callus induction in anther cultures of spring wheat. Plant Sci 1993;90:195-200.

64. Roy B, Mandal AB. Profuse microtillering of androgenic plantlets of elite indica rice variety IR 72. Asian J Biotechnol 2011;3:165-76.

65. Niroula RK, Bimb HP. Effect of genotype and callus induction medium on green plant regeneration from anther's of Nepalese rice cultivars. Asian J Plant Sci 2009;8:368-74.

66. Xa TT, Lang NT. Rice breeding for high grain quality through anther culture. Omonrice 2011;18:68-72.

67. Rout JR, Sharma NP. High frequency plantlet regeneration in rice anther callus cultures. Rice Genet Newslett 2001;29:175-82.

68. Sohn JK. Factors affecting pollen embryogenesis of rice anther culture. IRRN 2001;21:41-2.

69. Yang SF, Hoffman NE. Ethylene biosynthesis and its regulation in higher plants. Ann Rev Plant Physiol 1996;35:155-89.

70. Zhou H, Zheng Y, Konzak CF. Osmotic potential of media effecting green plant percentage in wheat anther culture. Plant Cell Rep 1991;10:63-6.

71. Hepler PK. Calcium: A central regulator of plant growth and development. Plant Cell 2005;17:2142-55.

72. Ghamemi M, Sarrafi A, Alibert G. The effect of silver nitrate, colchicines, cupric sulfate and genotype on the production of embryoids from anthers of tetraploid wheat (Triticum turgidum). Plant Cell Organ Cult 1994;36:355-9.

73. Dewi IS, Purwoko BS. Role of polyamines in inhibition of ethylene biosynthesis and their effects on rice anther culture development. Indones J Agric Sci 2008;9:60-7.

74. Lal D, Shashidhar HE, Godwa PH, Ashok TH. Callus induction and regeneration from in vitro anther culture of rice (Oryza sativa L.). Int J Agric Environ Biotechnol 2014;7:213-8.

75. Lee SY, Lee JH, Kwon TO. Selection of salt-tolerant doubled haploids in rice anther culture. Plant Cell Tissue Organ Cult 2003;74:143-9.

76. Lee SY, Lee JH, Kwon TO. Variation in anther culture response and fertility of backcrossed hybrids between indica and japonica rice (Oryza sativa). Plant Cell Tissue Organ Cult 2004;79:25-30.

77. Chaum S, Srianan B, Pichakum A, Kirdmanee C. An efficient procedure for embryogenic callus induction and double haploid plant regeneration through anther culture of Thai aromatic rice (Oryza sativa L. Subsp. Indica). In Vitro Cell Dev Biol Plant 2009;45:171-9.

78. Trejo-Tapia G, Amaya UM, Morales GS, Sanchez AD, Bonfil BM, 
Rodriguez-Monroy M, et al. The effects of cold-pretreatment, auxins and carbon source on anther culture of rice. Plant Cell Tissue Organ Cult 2002;71:41-6.

79. Patel JK, Subhash N, Fougat RS. In vitro callus induction and plantlet regeneration studies through anther culture in two indica rice (Oryza sativa L.) varieties. Curr Trends Biotechnol Pharm 2014;8:152-9.

80. Okamoto Y, Kinoshita A, Satake T. Enhancement of the frequency of callus formation and plant regeneration in rice anther culture by alternating temperature. Breed Res 2001;3:87-94.

81. Mandal N, Gupta S. Anther culture of an interspecific rice hybrid and selection of fine grain type with submergence tolerance. Plant Cell Tissue Organ Cult 1997;51:79-82.

82. Bhattacharya A, Mikkilineni V, Verma L, Palan B, Mali K, Char B. Evaluation of doubled haploid culture conditions and regeneration of an indica rice hybrid. Indian J Genet 2014;74:384-6.
83. Kumari M, Clarke HJ, Small I, Siddique KH. Albinism in plants: A major bottleneck in wide hybridization, androgenesis and doubled haploid culture. Crit Rev Plant Sci 2009;28:393-409.

84. Yamagishi M, Otani M, Higashi M, Fukuta Y, Fukui K, Yano M, et al. Chromosomal regions controlling anther culturability in rice (Oryza sativa L.). Euphytica 1998;103:227-34.

85. Asaduzzaman M, Bari MA, Rahman MH, Khatun N, Islam MA, Rahman M. In vitro plant regeneration through anther culture of five rice varieties. J Biol Sci 2003;3:167-71.

How to cite this article:
Tripathy SK, Swain D, Mohapatra PM, Prusti AM, Sahoo B, Panda S, Dash M,
Chakma B, Behera SK. Exploring factors affecting anther culture in rice (Oryza
sativaL.).JAppBiolBiotech.2019;7(02):87-92.DOI: 10.7324/JABB.2019.70216

